\title{
Comparison of Different Configurations for Piping Flexibility Analysis in Process Industry Applications
}

\author{
S. S. Deshpande ${ }^{1}$, V. Roshan ${ }^{2}$, M.Y. Soman ${ }^{3}$, P.J. Kasabe ${ }^{1}$ \\ ${ }^{I}$ (Department of Mechanical Engineering, Keystone School of Engineering, S. P. Pune University, India) \\ ${ }_{2}^{2}$ (Department of Mechanical Engineering, GITAM institute of Ttechnology, Visakhapatnam, India) \\ ${ }_{3}^{3}$ (Department of Mechanical Engineering, SITS , S. P. Pune University, India)
}

\begin{abstract}
The main purpose of the this study is to analyze the different flexibility configurations in process industry in the critical piping systems. Piping is the main transportation method for conveying fluids from one location to another within the industry. The design of flexibility and the routing of the piping systems is influenced by the stresses generated due to thermal effect and high pressure of the operating fluid. If the pipeline is pressurized it creates huge loads on the supports and elbows there by increasing overall pressure in the pipeline. In case of long pipes which are operating under high temperature gradient tend to expand significantly. In order to relieve the above stresses the expansion loops are provided in the system. The piping system should be designed to absorb the thermal expansion and not creating any loads on to the equipment .The recent trend is to use finite element analysis tools to ensure adequate flexibility requirements through forces and moments at the equipment nozzles within allowable. The paper reviews the comparison of different configuration of expansion loops with the methods with regard to prediction of forces, moments and stresses. The piping with a different configurations are compared with the results developed from the methods. We examine the Finite Element approach which is widely used in softwares like CAESAR II and general purpose ones like standard FEA packages like ANSYS and NASTRAN for analyzing the forces and moments and also the stresses and present the results for inverted $C$ type with equal and unequal lege lengths, $z$ shape and standard expansion loop configuration.
\end{abstract}

Keywords: Piping, Flexibility Analysis ,Finite element Method, Petroleum Refinery, Process Industry, CAE

\section{Introduction}

One major requirement in piping design is to provide adequate flexibility for absorbing the thermal expansion of the pipe. However, due to lack of quick method of checking, piping are often laid-out to be either too stiff or too flexible[1,3,6]. In either case, valuable time and material are wasted. As the pipe temperature changes from the installation condition to the operating condition, it expands or contracts. In the general term, both expansion and contraction are called thermal expansion. When a pipe expands it has the potential of generating enormous force and stress in the system[4]. The thermal expansion experienced by a long pipeline used between two equipments is very large. For a material like Carbon steel it is about 6 inch at a temperature of 650 degree Fahrenheit. The thermal expansion loads for such an amount of expansion on to the equipments are of the order of about 500 tonnes which is large enough to destruct the equipments connected by the pipeline. Hence there is a need to eliminate these forces and keep them to a lower range of values as per the equipment codes. The most common solution is to use a flexible configuration which means that the piping system should be able to absorb its own thermal expansion with the thermal expansion going else to the atmosphere . Common configurations include the expansion loops which are commonly found in Process industries to absorb the thermal expansion of the system and ensure adequate piping system flexibility $[1,3$, 4]. However several other flexibility configurations are possible such as $\mathrm{L}$ shaped, $\mathrm{Z}$ shaped to name a few .In the literature several methods exist for common configurations like expansion loops but for other configurations it is difficult to analyze by classical methods and hence modern tools of Finite Element Analysis are used . Nowadays the standard workhorse for design is the Finite element Method which forms an integral part of the overall design process in the world of Computer Aided engineering ( CAE) and several softwares such as NASTRAN, ANSYS and ABAQUS have become popular as they offer a speedy solution rather than experimentation which adds to time and cost. The present paper compares different configurations with modern FEA technique. We find that the use of the classical methods is somewhat diminished today due to much wider use of CAE practices and availability of standard configurations like symmetric expansion loops . Such methods are not available for other configurations like Z , Inverted C type and here FEA scores over the other traditional methods. 


\section{Problem Statement}

A practical problem considered here faced in a process piping industry pertaining to refinery is considered here for demonstration. These data refers to a piping system in a petrochemical refinery.we will analyze various configurations for a pipe routing of a fixed length of $100 \mathrm{ft}(30 \mathrm{~m})$ between two equipments . All the configurations are supposed to absorb the thermal expansion force. We have to determine the forces and moments. We have the other data as follows :
Temperatures:
$70^{\circ} \mathrm{F}$ to $482^{\circ} \mathrm{F}$

Pipe Size:

10 NPS Schedule 40

( Inside Diameter : 10.02 in and Outside Diameter 10.75 in )

Material of construction: A53 grade B ( As per ASTM specification, Plain carbon steel )

The main aim is:

1. To determine the forces and moments experienced at equipment locations

3. To determine also the stresses and finally

3. present a comparison of the results .

\section{Solution By Finite Element Method}

The finite element method plays a very important role in the product design and is widely used in almost all the fields. The method originated from matrix theory of structural analysis and then was complemented by mathematicians for partial differential equations. A detiled treatment of the method can be found in Logan [5] and here we present only the key concepts. The basic element to be used is a frame element which has the ability to bend and take the moments and also account for the axial elongtion and forces at the same time. This is a combination of beam and rod element. The nodal degrees of freedom for such an element are standard beam element with the degrees of freedom pertaining to axial displacement and vertical deflection and rotation. The stiffness matrix for which is given by

$$
[\mathrm{K}]=\left[\begin{array}{cccccc}
A E / L & 0 & 0 & -A E / L & 0 & 0 \\
0 & 12 E I / L^{3} & 6 E I / L^{2} & 0 & -12 E I / L^{3} & 6 E I / L^{2} \\
0 & 6 E I / L^{2} & 4 E I / L & 0 & -6 E I / L^{2} & 2 E I / L \\
-A E / L & 0 & 0 & A E / L & 0 & 0 \\
0 & -12 E I / L^{3} & -6 E I / L^{2} & 0 & 12 E I / L^{3} & -6 E I / L^{2} \\
0 & 6 E I / L^{2} & 2 E I / L & 0 & -6 E I / L^{2} & 4 E I / L
\end{array}\right]
$$

In this matrix $\mathrm{A}=$ Piping Cross sectional area $\left(\mathrm{in}^{2}\right), \mathrm{E}=$ Young's Modulus (psi), $\mathrm{L}=$ Length of the element (in) and $\mathrm{I}=$ Moment of Inertia $\left(\mathrm{in}^{4}\right)$

When we assmemble the stiffness matrix the size of global matrix depends on the number of elements used. As the structure ( piping ) is naturally discrete we will use per segment of piping one element. The Load is thermal expansion load as calculated by the formula $\mathrm{F}=\mathrm{AE} \alpha \Delta \mathrm{T}$, where $\alpha$ is the thermal expansion coefficient . The resrtaints at the equipment locations are eliminated by Guassian elimination and the program developed by the first author SADHANA ( Statics and Dynamics Higher end Analysis with Non Linear Algorithms ) is used to solve the system of equations. The Code developed by the author has been validated for a several test cases based on the programmes given by Chandrupatla and Belegundu[7].

We will now analyse various configurations

\section{Configuration 1: Inverted C type configuration with equal side leg lengths}

As stated in earlier section we finally obtain a global stiffness matrix of size $12 \times 12$ which after reduction due to boundary conditions becomes $6 \times 6$. The principal stresses and the forces and moments are obtained from primary variables of displacements and rotations and the results are as follows :

$\mathrm{S}_{1}=11.221 \mathrm{MPa}, \mathrm{S}_{2}=0 \mathrm{MPa}, \mathrm{S}_{3}=11.221 \mathrm{MPa}, \mathrm{M}_{\mathrm{A}}=2767.16 \mathrm{~N} \cdot \mathrm{m}, \mathrm{M}_{\mathrm{D}}=2767.16 \mathrm{~N} \cdot \mathrm{m}$

$\mathrm{R}_{\mathrm{AX}}=\mathrm{R}_{\mathrm{DX}}=454.005 \mathrm{~N}$ and $\mathrm{R}_{\mathrm{AY}}=\mathrm{R}_{\mathrm{DY}}=0$ 


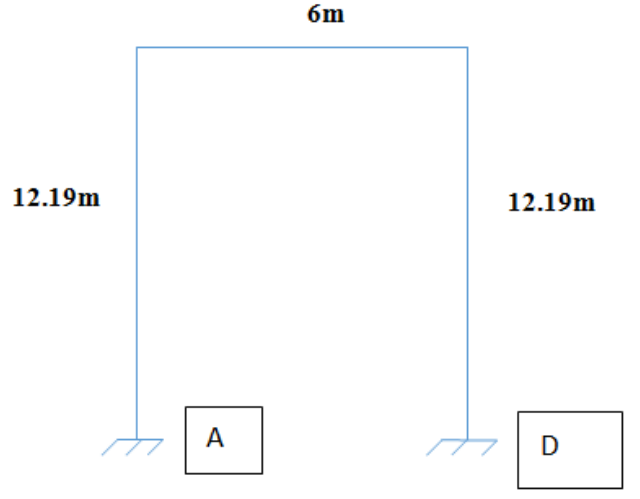

Fig. 1 Configuration of the piping system for anaysis . Locations A and D denote equipments .

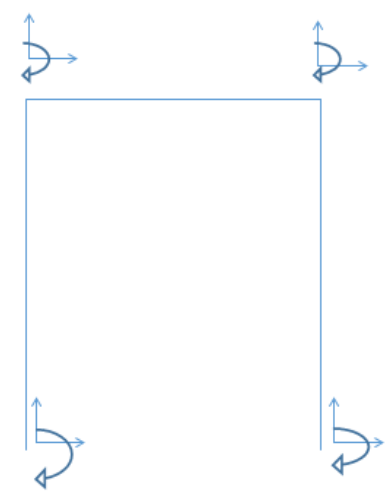

Fig. 2: Typical frame element discretization of piping with nodal degrees of freedom

Allowable Stress range as worked from code 31.3 is $=155.1 \mathrm{MPa}$

Thus we find that this configuration is much safe as the induced stresses are much lesser than the allowable stress range .

\section{Configuration 2: Inverted C type with unequal leg lengths}

The analysis is similar to the earlier case and the results for this configuration are as follows :

$\mathrm{S}_{1}=56.829 \mathrm{MPa}, \mathrm{S}_{2}=13.809 \mathrm{MPa}, \mathrm{S}_{3}=31.956 \mathrm{MPa}$

$\mathrm{M}_{\mathrm{A}}=14013.7 \mathrm{~N} . \mathrm{m}, \mathrm{M}_{\mathrm{D}}=7880.25 \mathrm{~N} . \mathrm{m}, \mathrm{R}_{\mathrm{AX}}=\mathrm{R}_{\mathrm{DX}}=2626.75 \mathrm{~N}$

$\mathrm{R}_{\mathrm{Y}}=496.77 \mathrm{~N}$

One can clearly see that now the streeses have increased. This is basically because the bending moments itself has increased due to asymmetry. This means that the equipments should be at the same level as far as possible rather than a height difference.

\section{Configuration 3: Z type}

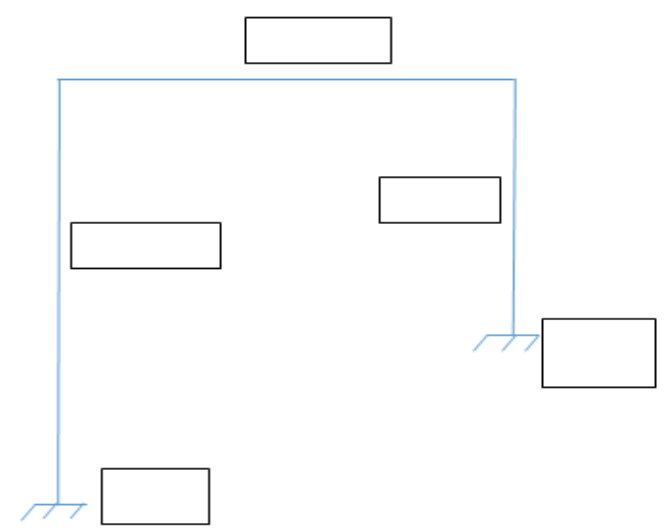

Fig. No. 3 Unsymmetric C Configuration of the piping system for anaysis 


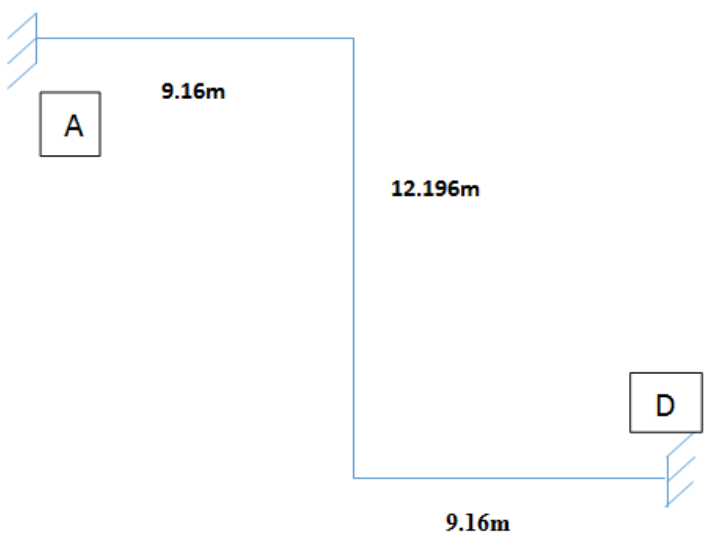

Fig. No. 4 : Z type flexibility Configuration

The Finite element discretizations is also shown and after the analysis is run, the following results were obtained

$\mathrm{S}_{1}=40.395 \mathrm{MPa}, \mathrm{S}_{2}=68.458 \mathrm{MPa}, \mathrm{S}_{3}=40.395 \mathrm{MPa}$

$\mathrm{M}_{\mathrm{A}}=9961.321 \mathrm{~N} \cdot \mathrm{m}, \mathrm{M}_{\mathrm{D}}=9961.321 \mathrm{~N} \cdot \mathrm{m}, \mathrm{R}_{\mathrm{X}}=2174.961 \mathrm{~N}$ and $\mathrm{R}_{\mathrm{Y}}=2768.36 \mathrm{~N}$

This is the most popular configuration in the process industry[2] and requires guide supports so that the expansion of the piping between the equipments located at A and D is driven within the expansion loop . The finite element analysis will now involve use of 7 elements with restraints at equipments A and D ( fixed or full anchor type ) and at guide supports only $\mathrm{x}$ translation allowed and all other degrees of freedom fixed. The size of the stiffness matrix is 21 by 21 and after restraints application it reduces to $14 \times 14$.

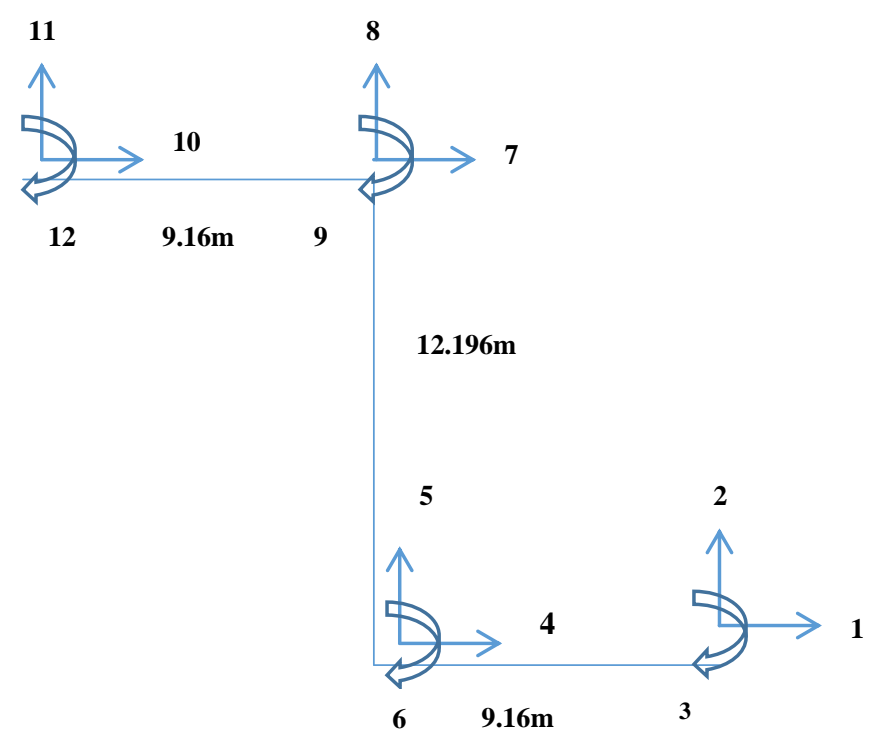

\section{Configuration 4 : Symmetric Expansion Loop}

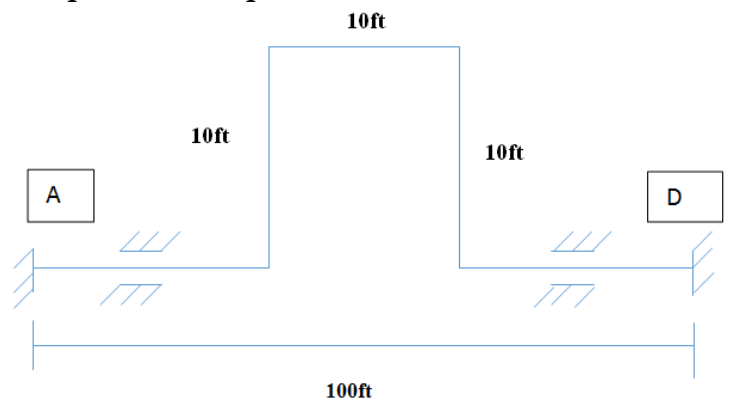

Fig. 5 : Symmetric Expansion Loop Configuration of the piping system for anaysis 
The analysis results are as follows :

$\mathrm{S}_{1}=50.25 \mathrm{MPa}, \mathrm{S}_{2}=0 \mathrm{MPa}, \mathrm{S}_{3}=0 \mathrm{MPa}$

$\mathrm{M}_{\mathrm{A}}=4961.81 \mathrm{~N} \cdot \mathrm{m}, \mathrm{M}_{\mathrm{D}}=4961.81 \mathrm{~N} \cdot \mathrm{m}, \mathrm{R}_{\mathrm{X}}=9900 \mathrm{~N}$ and $\mathrm{R}_{\mathrm{Y}}=9900 \mathrm{~N}$.

\section{Comparison Of Results}

A tabular comparison of all configurations is given below :

\begin{tabular}{|c|c|c|}
\hline Sr. No. & Type of configuration & Results \\
\hline 1 & $\begin{array}{l}\text { Inverted } \mathrm{C} \text { type } \\
\text { configuration with equal } \\
\text { side leg lengths }\end{array}$ & $\begin{array}{c}\mathrm{S}_{1}=11.221 \mathrm{MPa}, \mathrm{S}_{2}=0 \mathrm{MPa}, \mathrm{S}_{3}=11.221 \mathrm{MPa} \\
\mathrm{M}_{\mathrm{A}}=2767.16 \mathrm{~N} \cdot \mathrm{m}, \mathrm{M}_{\mathrm{D}}=2767.16 \mathrm{~N} \cdot \mathrm{m} \\
\mathrm{R}_{\mathrm{AX}}=\mathrm{R}_{\mathrm{DX}}=454.005 \mathrm{~N} \\
\mathrm{R}_{\mathrm{AY}}=\mathrm{R}_{\mathrm{DY}}=0 \\
\text { Allowable Stress range as per } 31.3=155.1 \mathrm{MPa} \\
\text { Factor of Safety }=12\end{array}$ \\
\hline 2 & $\begin{array}{l}\text { Inverted } C \text { type with } \\
\text { unequal leg lengths }\end{array}$ & $\begin{array}{c}\mathrm{S}_{1}=56.829 \mathrm{MPa}, \mathrm{S}_{2}=13.809 \mathrm{MPa}, \mathrm{S}_{3}=31.956 \mathrm{MPa} \\
\mathrm{M}_{\mathrm{A}}=14013.7 \mathrm{~N} . \mathrm{m}, \mathrm{M}_{\mathrm{D}}=7880.25 \mathrm{~N} . \mathrm{m} \\
\mathrm{R}_{\mathrm{AX}}=\mathrm{R}_{\mathrm{DX}}=2626.75 \mathrm{~N} \\
\mathrm{R}_{\mathrm{Y}}=496.77 \mathrm{~N} \\
\text { Allowable Stress range as per } 31.3=155.1 \mathrm{MPa} \\
\text { Factor of Safety }=3.0\end{array}$ \\
\hline 3 & $\mathrm{Z}$ type & $\begin{array}{c}\mathrm{S}_{1}=40.395 \mathrm{MPa}, \mathrm{S}_{2}=68.458 \mathrm{MPa}, \mathrm{S}_{3}=40.395 \mathrm{MPa} \\
\mathrm{M}_{\mathrm{A}}=9961.321 \mathrm{~N} . \mathrm{m}, \mathrm{M}_{\mathrm{D}}=9961.321 \mathrm{~N} . \mathrm{m} \\
\mathrm{R}_{\mathrm{X}}=2174.961 \mathrm{~N}, \mathrm{R}_{\mathrm{Y}}=2768.36 \mathrm{~N} \\
\text { Allowable Stress range as per } 31.3=155.1 \mathrm{MPa} \\
\text { Factor of Safety }=3.5\end{array}$ \\
\hline 4 & $\begin{array}{l}\text { Symmetric Expansion } \\
\text { Loop }\end{array}$ & $\begin{array}{l}\mathrm{S}_{1}=50.25 \mathrm{MPa}, \mathrm{S}_{2}=0 \mathrm{MPa}, \mathrm{S}_{3}=0 \mathrm{MPa} \\
\mathrm{M}_{\mathrm{A}}=4961.81 \mathrm{~N} . \mathrm{m}_{\mathrm{D}} \mathrm{M}_{\mathrm{D}}=4961.81 \mathrm{~N} . \mathrm{m}, \mathrm{R}_{\mathrm{X}}=9900 \mathrm{~N} \text { and } \mathrm{R}_{\mathrm{Y}}=9900 \mathrm{~N} \\
\text { Allowable Stress range as per } 31.3=155.1 \mathrm{MPa}, \text { Factor of safety }=3.0\end{array}$ \\
\hline
\end{tabular}

\section{Conclusion}

We have presented here a critical assessment of several flexibility configurations in this paper. The standard practice in the process industry as well as the petroleum refineries is the expansion loops but we present here that several other configurations are also possible which can be equally competent with symmetric expanaion loop. There are situations where a straight piping may not be applicable due to space restrainst and in this case how much is the stress difference due to all safe configuartions is a big question . The present analysis throws more light on this and we hope that the piping design engineer can get some more idea rather than using a blind or earlier practice. Among all the configurations we find that the symmetric expansion loop .generates lower loads but the bending moments and stresses are quite high . On the contrary the $\mathrm{Z}$ configuration and the Inverted $\mathrm{C}$ with equal leg lengths prove to be much more safe. These configurations also have less space requirement and hence it is the authors opinion that they are more optimal for practical industry cases. We hope that a simple FEA/ CAE approach while designing can help us a lot in decision making and the practical piping design engineers working in power plants, and process industry and petroleum refineries will benefit from this approach.

\section{References}

[1] M .W.Kellogg, The Design of Piping Systems (Martino Fine books, 2007).

[2] J.J.McKetta (ed), Piping Design Handbook (CRC Press, 1992)

[3] M.L.Nayyar, Piping Handbook,(McGrawHill , $7^{\text {th }}$ edition,1999)

[4] G.K.Sahu, Handbook of Piping Design (New Age International Publishes, 2014).

[5] D.A.Logan, A first course in Finite Element Method, (Cengage Learning, 2015)

[6] S.S.Deshpande, Notes on Piping stress analysis for industrial training programme for various companies like ESSAR steels, Thermax, Larsen and toubro etc.( Asian Academy of Professional Training , Pune , 2012)

[7] Chandrupatla and Belegundu, Introduction to Finite Elements in Engineering (Pearson 2015) 